Electronic Supplementary Information

\title{
Conversion of Glycerol to Hydrocarbon Fuels via Bifunctional Catalysts
}

\author{
Yang Xiao and Arvind Varma* \\ School of Chemical Engineering, Purdue University, 480 Stadium Mall Drive, West Lafayette, \\ Indiana 47907, United States \\ Tel.: +1-(765) 494-4075. Fax: +1-(765) 494-0805. E-mail: avarma@purdue.edu.
}




\section{Experimental}

\section{Materials}

Chloroplatinic acid hydrate (99.9\% metal basis) and palladium (II) nitrate hydrate (99.8\% metals basis) were used as metal precursors, both from Alfa Aesar. ZSM-5 $(\mathrm{Si} / \mathrm{Al}=40)$ of ammonium form was supplied by Zeolyst International. The following chemicals, all ACS grade, were obtained from Mallinckrodt Chemicals: pure glycerol, 37 wt $\% \mathrm{HCl}$ and $\mathrm{NaOH}$ pellets. The following chemical standards were from SigmaAldrich: acetaldehyde, benzene, cumene, ethylene, hydroxyacetone (acetol), methane, propanal, propenal (acrolein), propylene, toluene, m-xylene, o-xylene, p-xylene. Ultrahigh purity grade gases $\left(\mathrm{H}_{2}, \mathrm{He}, \mathrm{O}_{2}, \mathrm{CH}_{4}, \mathrm{C}_{2} \mathrm{H}_{6}\right.$ and $\left.\mathrm{C}_{3} \mathrm{H}_{8}\right)$ were purchased from Indiana Oxygen. The $0.5 \% \mathrm{Pt} / \mathrm{Al}_{2} \mathrm{O}_{3}$ (metal dispersion $=31 \pm 0.5 \%$ ) standard used for calibration of chemisorption measurements was obtained from Micromeritics.

\section{Catalyst Preparation}

ZSM-5 $(\mathrm{Si} / \mathrm{Al}=40)$ of ammonium form was converted to its $\mathrm{H}$-form $(\mathrm{H}-\mathrm{ZSM}-5)$ by calcining in air at $500{ }^{\circ} \mathrm{C}$ for $4 \mathrm{~h}^{2,3}$. Pt and Pd were loaded on H-ZSM-5 by the impregnation method, to obtain $5 \mathrm{wt} \% \mathrm{Pt} / \mathrm{H}-\mathrm{ZSM}-5$ and $5 \mathrm{wt} \% \mathrm{Pd} / \mathrm{H}-\mathrm{ZSM}-5$ catalysts, respectively. Briefly, Pt and Pd precursors were dissolved separately in deionized water, and then added dropwise to the well-stirred H-ZSM-5 slurry, with $\mathrm{pH}=5-6$ and stirring continued for at least $8 \mathrm{hrs}$ at room temperature for each metal loading. The slurry was then rinsed, dried in air at $100{ }^{\circ} \mathrm{C}$. As noted above, the Pt and Pd loadings were both 5 wt\%, while H-ZSM-5 was the H-form ZSM-5 with a Si/Al ratio of 40 . For this reason, in 
later sections the metal loadings and details of H-ZSM-5 are not noted explicitly when describing the catalysts. Thus, e.g., Pt/H-ZSM-5 refers to $5 \mathrm{wt} \%$ Pt placed on $\mathrm{H}-$ form ZSM-5 with a Si/Al ratio of 40 .

\section{Catalyst characterization}

The physisorption properties of the catalysts, including BET surface area, pore size distribution, average pore volume and pore diameter, were measured using a Micromeritics ASAP 2000 apparatus, where nitrogen was used as adsorbent gas. Degassing was performed at $280{ }^{\circ} \mathrm{C}$ for $6 \mathrm{hrs}$ before measurements. The Pt dispersion was obtained using the $\mathrm{H}_{2}-\mathrm{O}_{2}$ titration approach ${ }^{1}$, where the calibration was done using the $0.5 \% \mathrm{Pt} / \mathrm{Al}_{2} \mathrm{O}_{3}$ standard described in Materials section. The surface morphology of catalyst samples was obtained using a FEI-Tecnai transmission electron microscope (TEM), operated at $200 \mathrm{kV}$ with $\mathrm{LaB}_{6}$ source. The samples were prepared by suspending the catalyst particles in water, collecting the fines, and placing them on a 200 copper mesh with lacey carbon film coating, followed by drying in air. The powder X-ray diffraction (XRD) was performed on a Rigaku SmartLab X-ray diffractometer with a $\mathrm{Cu}$ $\mathrm{K} \alpha$ radiation source. Elemental analysis of fresh $5 \% \mathrm{Pd} / \mathrm{H}-\mathrm{ZSM}-5$, 3-times used 5\% $\mathrm{Pd} / \mathrm{H}-$ ZSM-5, fresh $5 \% \mathrm{Pt} / \mathrm{H}-\mathrm{ZSM}-5$, and 3-times used 5\%Pt/H-ZSM-5 was carried out by ICPAES method.

TPD experiments were performed using a Micromeritics Autochem II 2920 Chemisorption analyzer equipped with an Agilent 5975C mass selective detector (MSD) 
to identify the gaseous species evolved from the catalyst samples. The samples were placed between two quartz wool plugs inside a U-shaped quartz cell held within a clamshell furnace, with $50 \mathrm{~cm}^{3} \mathrm{~min}^{-1}$ flowing UHP helium at ambient temperature for $1 \mathrm{~h}$, and heated to $873 \mathrm{~K}\left(0.167 \mathrm{~K} \mathrm{~s}^{-1}\right)$.

\section{Catalyst activity testing}

The experiments were conducted in a continuous flow system as shown in Figure S1. The catalysts were packed in a stainless steel fixed-bed reactor with $\mathrm{OD}=12.7 \mathrm{~mm}$ and ID $=10.2 \mathrm{~mm}$, where stainless steel meshes and quartz wool plugs were inserted at both ends. Prior to the GTH reaction, the catalysts were activated at $400^{\circ} \mathrm{C}, 1 \mathrm{~atm}$ for $4 \mathrm{~h}$ under a gas mixture $\left(\mathrm{H}_{2}-25 \%, \mathrm{~N}_{2}-75 \%\right)$ flow. Pure glycerol was heated to $300^{\circ} \mathrm{C}$ to ensure its evaporation prior to being pumped (by an IP 25 Isocratic pump from Dionex) into the reactor. The product mixture was condensed in a glass condenser, cooled down by propanediol circulation (to $-20{ }^{\circ} \mathrm{C}$ ) controlled by a circulator (Thermo Haake C10). The liquid products were collected every $10 \mathrm{~min}$ and the compositions were analyzed, while the gaseous products were analyzed on-line every $5 \mathrm{~min}$. The standard reactor operating conditions were $400{ }^{\circ} \mathrm{C}, 1 \mathrm{~atm}$ total pressure, $2.25 \mathrm{~g}$ catalyst, mixed gas of $\mathrm{N}_{2}$ and $\mathrm{H}_{2}$ at flow rates $100 \mathrm{~mL} / \mathrm{min}$ and $15-200 \mathrm{~mL} / \mathrm{min}$ respectively, and pure glycerol feed rate $0.3 \mathrm{~mL} / \mathrm{h}$ (liquid, at room temperature). All experiments were conducted under excess hydrogen flow (feed molar ratio of $\mathrm{H}_{2}$ to glycerol 10). A blank test with packing inert materials, instead of the catalyst, was conducted under the standard reaction conditions. It was found that glycerol conversion was $<2 \%$. All experiments have mass 
balances of $90 \pm 3 \%$. Possible factors affecting mass balance include liquid or solid holdup in the system, including the reactor and condenser, and possible coke deposit on the catalysts.

\section{Composition analysis}

Since typical products split into three phases: gaseous phase, organic liquid phase (upper phase) and aqueous liquid phase (lower phase), these three phases were analyzed separately. Both liquid product samples were analyzed by a GC-MS (LECO Pegasus 4D GCxGC-TOF), coupled with an auto sampler (CTC, GC-xt) and equipped with a DBWAX column $(30 \mathrm{~m} \times 0.32 \mathrm{~mm})$. For routine analysis, the organic liquid samples were analyzed by a gas chromatograph (Agilent GC 6890) equipped with flame ionization detector and a DB-WAX (30 m x $0.32 \mathrm{~mm})$ column, while the aqueous liquid samples were analyzed by a gas chromatograph (Agilent GC 5890) equipped with flame ionization detector and a Select Biodiesel for glycerides ultiMetal Column $(15 \mathrm{~m} * 0.32$ $\mathrm{mm}, \mathrm{ID}=0.10 \mu \mathrm{m}$ ) with a retention gap. The gaseous product was analyzed by a micro-GC (Agilent 3000A Micro GC) equipped with a Mol-Sieve 5A column and a Plot U column. Calibration was performed for all the components. 
Table S1. BET and chemisorption results

BET results

Chemisorption results

Materials

$\begin{array}{cccc}\begin{array}{c}\text { Specific surface } \\ \text { area }\end{array} & \text { Average pore diameter } & \text { Metal dispersion } & \text { Metal particle size } \\ & (\mathrm{nm}) & (\%) & (\mathrm{nm}) \\ \left(\mathrm{m}^{2} / \mathrm{g}\right) & & & \end{array}$

H-ZSM-5

476

0.58

Pt/H-ZSM-5

421

0.52

24.3

3.6

Pd/H-ZSM-5

437

0.53

29.7

3.2 
Table S2. Catalyst AES-ICP element analysis results

\begin{tabular}{lcccc}
\hline & Fresh & 3-times Used & Fresh & 3-times Used \\
Materials & $5 \% \mathrm{Pd} / \mathrm{H}-\mathrm{ZSM}-5$ & $5 \% \mathrm{Pd} / \mathrm{H}-\mathrm{ZSM}-5$ & $5 \% \mathrm{Pt} / \mathrm{H}-\mathrm{ZSM}-5$ & $5 \%$ Pt/H-ZSM-5 \\
& & & & \\
Metal content, $\%$ & 4.73 & 4.39 & 5.04 & 4.82 \\
\hline
\end{tabular}


Table S3. Catalyst $\mathrm{NH}_{3}-\mathrm{TPD}$ results

\begin{tabular}{lccc}
\hline & & & \\
Materials & H-ZSM-5 & Pd/H-ZSM-5 & Pt/H-ZSM-5 \\
& & & \\
H/Al ratio & 0.88 & 0.78 & 0.17 \\
H/Metal ratio & - & & \\
& & 0.63 & 0.13 \\
\hline
\end{tabular}


Table S4. Catalyst XPS results

Elements, atomic \%

$\mathrm{Si}$

$\mathrm{O}$

$\mathrm{Pt}$

$\mathrm{Pd}$

H-ZSM-5

33.26

66.14

0

0

Pt/H-ZSM-5

33.39

66.08

0.53

0

Pd/H-ZSM-5

31.98

66.95

0

1.06 


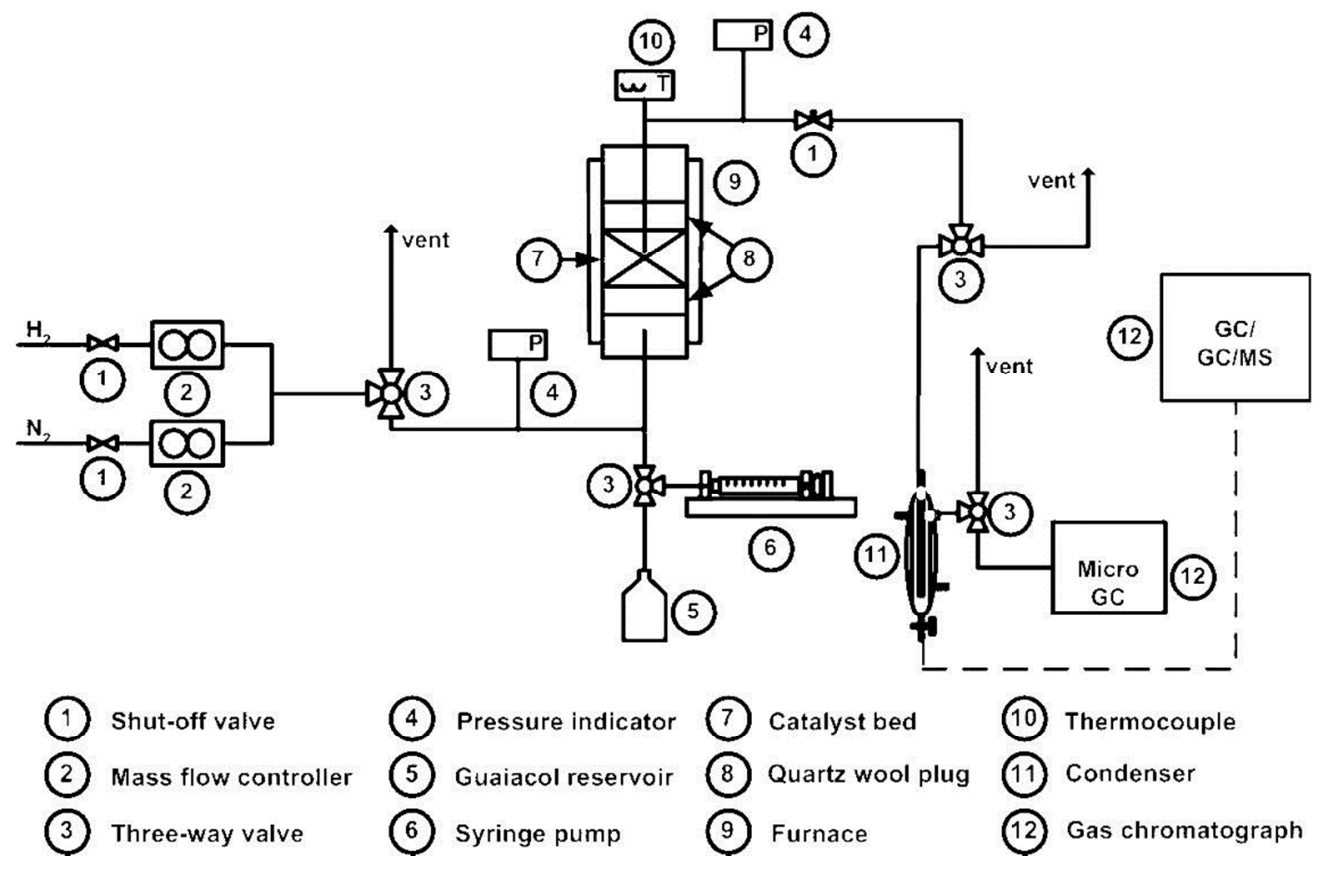

Figure S1. Schematic diagram of the experimental setup 

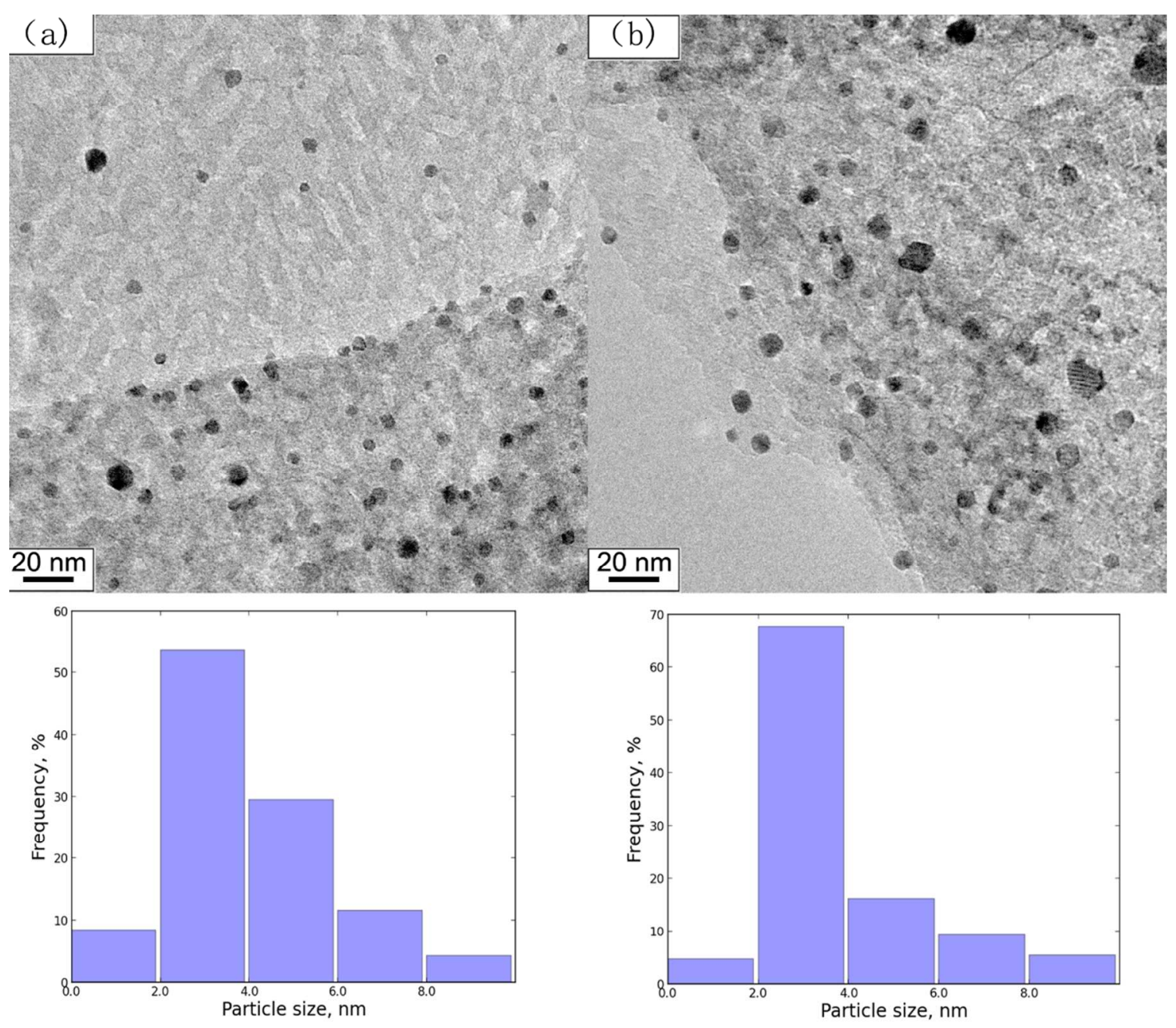

Figure S2. TEM scans and particle size distributions for a) Pt/H-ZSM-5 and b) Pd/HZSM-5 


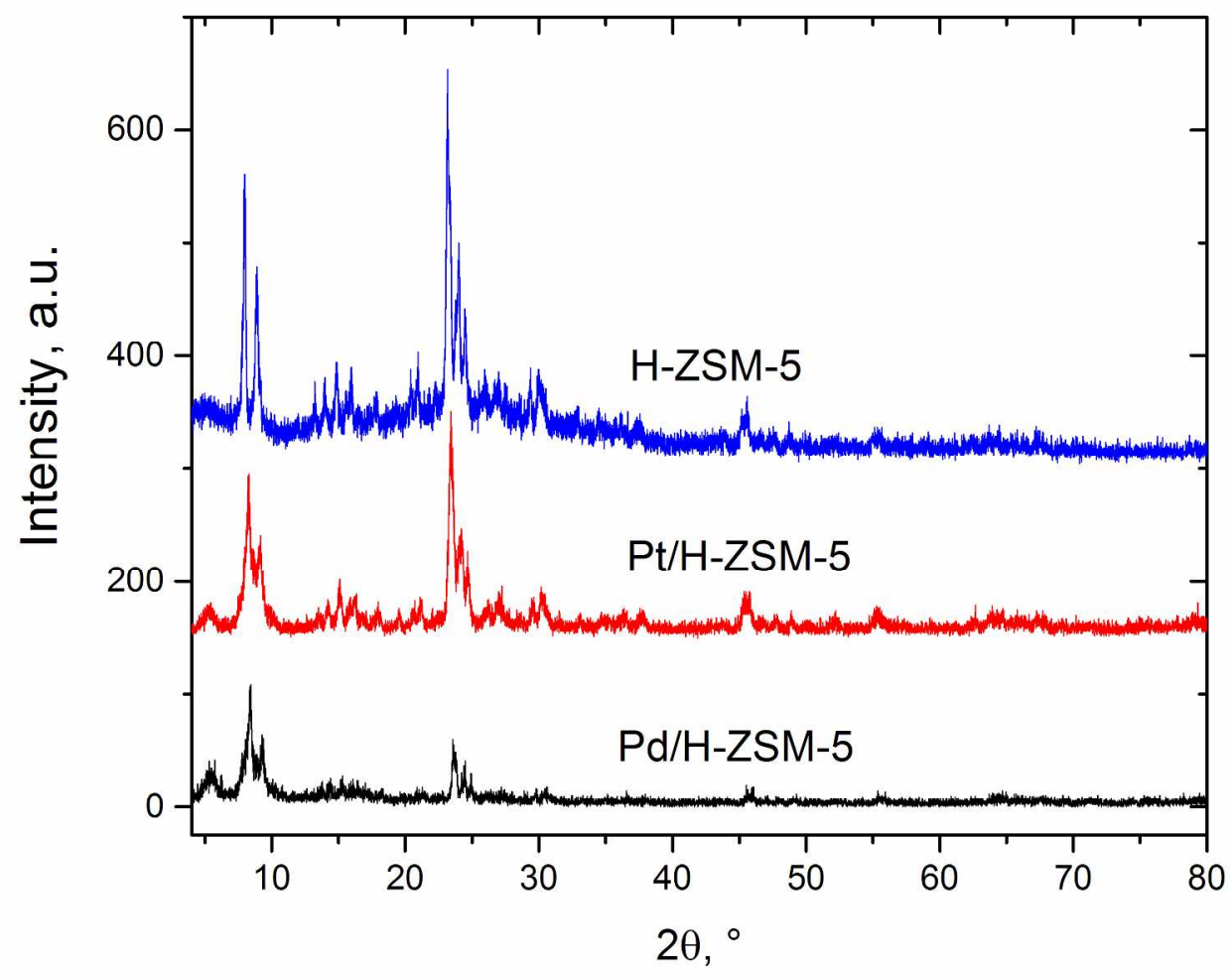

Figure S3. XRD patterns of H-ZSM-5, Pt/H-ZSM-5 and Pd/H-ZSM-5 


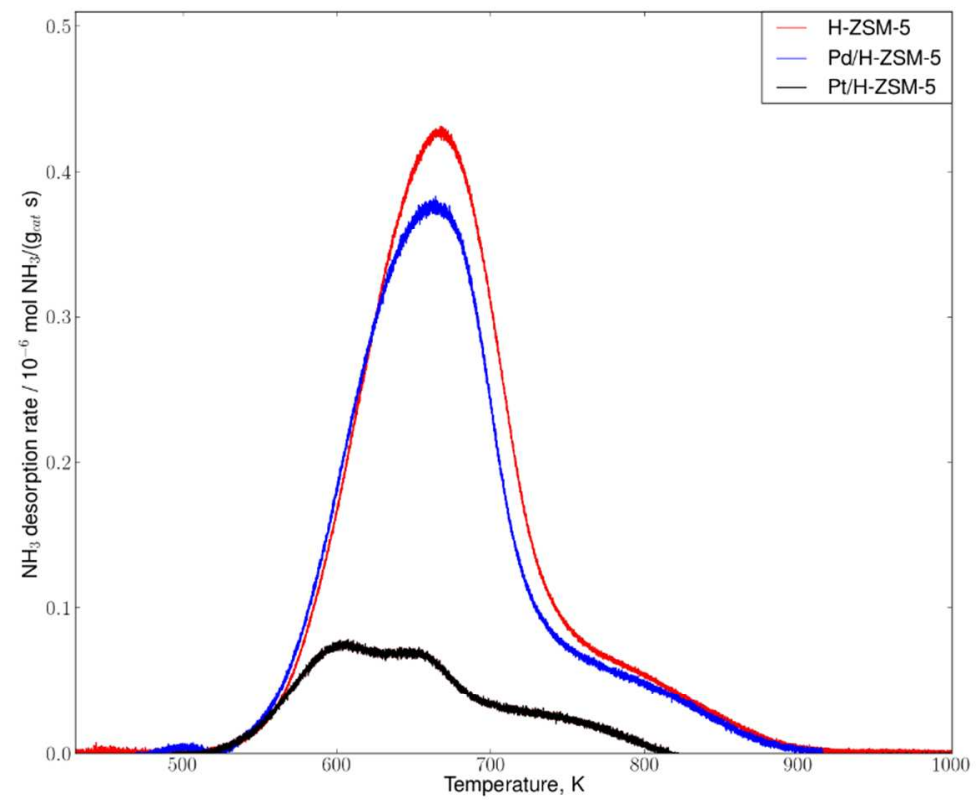

Figure S4. Catalyst NH3-TPD rate plot 


\section{References}

1. Benson, J. E.; Boudart, M. Hydrogen-Oxygen Titration Method for the Measurement of Supported Platinum Surface Areas. J Catal 1965, 4, 704-710.

2. Chiang, H.; Bhan, A. Catalytic consequences of hydroxyl group location on the rate and mechanism of parallel dehydration reactions of ethanol over acidic zeolites. $J$ Catal 2010, 271, 251-261.

3. Di Iorio, J. R.; Bates, S. A.; Verma, A. A.; Delgass, W. N.; Ribeiro, F. H.; Miller, J. T.; Gounder, R. The Dynamic Nature of Bronsted Acid Sites in $\mathrm{Cu}$-Zeolites During NOx Selective Catalytic Reduction: Quantification by Gas-Phase Ammonia Titration. Top Catal 2015, 58, 424-434. 